\title{
Phytohormonal signaling in plant responses to aphid feeding
}

\author{
Iwona Morkunas • Van Chung Mai • \\ Beata Gabryś
}

Received: 16 June 2010/Revised: 3 March 2011 / Accepted: 24 March 2011/Published online: 8 April 2011

(C) The Author(s) 2011. This article is published with open access at Springerlink.com

\begin{abstract}
Aphid feeding induces various defense signaling mechanisms in plants. The recognition of feeding activities by plants occurs through the use of transmembrane pattern recognition receptors (PRRS) or, acting largely inside the cell, polymorphic nucleotide-binding leucine-rich-repeat (NB-LRR) protein products, encoded by most $\mathrm{R}$ genes. Activation may induce defensive reactions which are the result of highly coordinated sequential changes at the cellular level comprising, among other changes, the synthesis of signaling molecules. The ensuing plant responses are followed by the transmission of defense response signal cascades. Signals are mediated by bioactive endogenous molecules, i.e. phytohormones, such as jasmonic acid (JA), salicylic acid (SA), ethylene (ET), abscisic acid (ABA), gibberellic acid (GA) and free radicals such as hydrogen peroxide $\left(\mathrm{H}_{2} \mathrm{O}_{2}\right)$ and nitric oxide (NO) which independently provide direct chemical resistance. Plant-induced defenses are also regulated by a network of inter-connecting signaling pathways, in which JA, $\mathrm{SA}$, and ET play dominant roles. Both synergistic and
\end{abstract}

Communicated by A. K. Kononowicz.

I. Morkunas $(\bowtie) \cdot$ V. C. Mai

Department of Plant Physiology, Faculty of Horticulture and Landscape Architecture, Poznań University of Life Sciences, Wołyńska 35, 60-637 Poznan, Poland

e-mail: morkunas@jay.up.poznan.pl

B. Gabryś

Department of Botany and Ecology, Faculty of Biological Sciences, University of Zielona Góra, Prof. Z. Szafrana 1, 65-516 Zielona Gora, Poland

V. C. Mai

Department of Plant Physiology, Faculty of Biological Sciences, University of Vinh, Le Duan 182, Vinh, Vietnam inhibitory aspects of the cross-talk among these pathways have been reported. This paper presents molecular mechanisms of plant response to aphid feeding, the precise activation of various endogenous bioactive molecules signaling in the response of many plant species and their participation in the regulation of numerous defense genes, which lead to a specific metabolic effect. Selected important points in signal transduction pathways were also discussed in studies on plant response to aphid feeding.

Keywords Aphid feeding - Plant defense response . Signal molecules $\cdot$ Signaling pathway $\cdot$ Cross-talk
Abbreviations
JA Jasmonic acid
SA Salicylic acid
ET Ethylene
ABA Abscisic acid
GA Gibberellic acid
$\mathrm{H}_{2} \mathrm{O}_{2}$ Hydrogen peroxide
NO Nitric oxide

\section{Introduction}

The plant-aphid interaction is a dynamic system subjected to continual variation and change (Mello and Silva-Filho 2002). In this system, aphids evolve and develop many strategies to overcome plant defense barriers which allow them to feed, grow and reproduce on their host plants. The first activity of aphids is to determine if a plant is suitable for them or not. The cues winged aphids use to decide on landing are both visual and chemical (Pettersson et al. 
2007). After landing on a plant, aphids ingest phloem sap from their hosts through narrow piercing-sucking mouthparts called stylets. During probing, aphids' stylets transiently puncture the epidermis, mesophyll, and parenchyma cells to the phloem, and this mechanical damage may influence plant responses to infestation (Tjallingii and Hogen Esch 1993). Aphids regularly puncture cells along the stylet pathway and ingest cytosolic samples. Aphids of all ages use $75 \%$ of their total stylet length to reach the phloem (Elliott and Hodgson 1996). The aphid stylet pathway is intercellular before the phloem is reached and brief symplast punctures are very frequent (Tjallingii and Hogen Esch 1993). Aphids penetrate plant tissues primarily via the intracellular route and their impact on the host is thought to be largely due to a reduction of the photosynthesis process, withdrawal of plant sap and injection of saliva. Aphid probing may be influenced by changes in the chemical content of the sieve element sap or by physiological changes induced by aphid saliva (Prado and Tjallingii 1997; Hays et al. 1999; Telang et al. 1999; Ponder et al. 2001). Aphids secrete a proteinaceous salivary sheath that lines the stylet path, as well as watery saliva that contains numerous enzymes such as oxidases, pectinases and cellulases, which cause cell wall breakdown (Goggin 2007). Giordanengo et al. (2010) showed that transcriptional reprogramming by aphids includes several genes involved in cell wall metabolism and remodeling. Feeding on Arabidopsis and Apium graveolens, B. brassicae and M. persicae, respectively, induces systemic over-expression of cell wall-associated protein kinases, pectin acetyl esterase, expansin and cellulose synthase, while transcription of pectin esterase inhibitors is down-regulated. It has also been suggested that a common pattern may be found in gelling saliva composition between different aphid species, whereas watery saliva compositions differ considerably (Will et al. 2009). Gelling saliva is primarily composed of proteins (including phenoloxidases, peroxidases, pectinases, $\beta$-glucosidases), phospholipids, and conjugated carbohydrates. Watery saliva is a more complex mixture of enzymes and other components, capable of eliciting plant defense signals (Hori 1976; Baumann and Baumann 1995; Urbanska et al. 1998; Miles 1999). Mutti (2006) also reported that injected saliva may play a crucial role in the prevention of the plant's wound responses, but may also elicit the plant's reaction, resulting in damage during a later stage of the infestation. The salivary enzymes of aphids are similar to enzymes with identical functions in plants, i.e. oxidases and enzymes that depolymerize polysaccharides, and are injected in very small amounts relative to their counterparts in the plant. Damage to plants triggers defensive biochemical responses and it is suggested that the injected enzymes serve mainly to divert or counter responses at the immediate interface between the stylet and plant tissues (Miles 1999). Research into the identification of M. persicae salivary proteins carried out by Harmel et al. (2008) revealed the presence of glucose oxidase, glucose dehydrogenase, NADH dehydrogenase, $\alpha$-glucosidase and $\alpha$-amylase. Elicitors have also been discovered in the saliva of some chewing insects: glucose oxidase in the saliva of Helicoverpa zea, $\beta$-glucosidase in that of Pieris brassicae, volicitin in the case of Spodoptera exigua and caeliferin in Schistocerca americana. Both $\beta$-glucosidase and volicitin have been found to induce the release of volatile organic compounds which are attractive to the natural enemies of attacking insects. Will et al. (2007) recently demonstrated that aphid saliva also contains calcium $\left(\mathrm{Ca}^{2+}\right)$ binding proteins and can reverse phloem occlusion, which is triggered by a $\mathrm{Ca}^{2+}$ flux in response to wounding. The ability to prevent sieve tube plugging is an important adaptation that allows aphids to remain at a single feeding site for hours at a time. Aphids seem to have developed a range of physical and chemical measures to limit the amount of $\mathrm{Ca}^{2+}$ influx in response to stylet insertion and minimized by the minute stylet volume. Turgor-dependent $\mathrm{Ca}^{2+}$ influx, possibly mediated by the mechanically sensitive $\mathrm{Ca}^{2+}$ channels, must therefore be limited. The components of the sheath and watery saliva play a pivotal role in establishing physical and chemical constraints on the rise of $\mathrm{Ca}^{2+}$ concentration. Most likely, sheath saliva prevents the influx of $\mathrm{Ca}^{2+}$ from the apoplast by sealing the stylet puncture site, while watery saliva may prevent the plugging and sealing of sieve plates by interaction with the components of sieve element sap. The wound size alone, caused by the impalement of stylets and microcapillaries with a tip diameter of $1 \mu \mathrm{m}$ into sieve elements, was compared and the consequences were observed. However, the stylet puncture is readily sealed by sheath saliva, which strongly reduces the influx of $\mathrm{Ca}^{2+}$ (Will and van Bel 2006).

The electrical penetration graph (EPG) technique facilitates electrical monitoring of plant penetration by aphids with piercing mouthparts and the recording of signal waveforms reflecting different insect activities such as mechanical stylet work, saliva secretion and sap ingestion (Tjallingii 2006). Four periods of salivary secretion have been identified by EPG, i.e. one period of gelling salivation and three periods of watery salivation: (1) intercellular sheath salivation that envelops the stylet; (2) intracellular salivation into cells along the stylet path; (3) initial phloem salivation; and (4) phloem-feeding salivation (Cherqui and Tjallingii 2000).

As described above, the signals responsible for the activation of plant defenses to aphid feeding are not only mechanical, but also chemical, through the action of particular molecules commonly called elicitors which are present in saliva. Kuśnierczyk et al. (2008) reported that the content of oral secretions may play a role in the 
recognition of the attacker by the plant; however, the disruption of cell wall and membrane integrity, either by enzymes introduced through the penetrating stylet or simply by mechanical damage following the incursion, is likely to be the first factor that triggers the plant response.

As economically important pests of agricultural crops, aphids not only ingest phloem sap from host plants through the narrow piercing-sucking mouth, but also cause much damage. Common symptoms of aphid infestation found in plants include gall-formation, chlorosis, necrosis, wilting, stunting, and malformation of new growth (Guerreri and Digilio 2008). Miles (1989) reported that the injection of aphid saliva can be extremely toxic to plants around the stylet tracks, causing chloroplast disruption or even alteration of the hormonal balance of the plant.

Regardless of the types of direct damage, aphids produce huge quantities of honeydew, crystals which may accumulate on leaf surfaces. Often, a black layer of saprophytic fungi stratifies on honeydew blocking the stomata, causing leaf fall and impairing photosynthesis. In many cases such indirect damage may be far worse than the simple withdrawal of plant sap. Moreover, aphids transmit bacterial and viral phytopathogens to their hosts. In the case of virus-transmission, pathogenic symptoms add to those caused by aphid attack. There is no treatment for aphid-transmitted phytopathogenic viruses other than the prevention of aphid probing (Guerreri and Digilio 2008). Even aphid species that do not trigger visible diagnostic symptoms cause some physiological changes in their hosts. For example, the pea aphid (Acyrthosiphon pisum) diverts nitrogen from the apical growth zones of alfalfa (Medicago sativa) to its feeding sites (Girousse et al. 2005). The greenbug aphid (Schizaphis graminum) and the Russian wheat aphid (Diuraphis noxia) also induce an increase in essential amino acids in the phloem sap, apparently by triggering the breakdown of proteins in infested wheat leaves (Triticum spp.) (Sandström et al. 2000). Thus, aphids enhance the nutritional quality of their feeding sites by increasing the import of resources from other sites in the plant, mobilizing local resources, and blocking their export to other organs.

Plants have developed different mechanisms to reduce aphid attack. It has been suggested that two different processes are involved in the elicitation of plant defense (Smith and Boyko 2007). One process involves a gene-forgene recognition of aphid-derived elicitors by plant resistance genes, followed by the activation of aphid resistance and defense responses. The second process involves the recognition of aphid-inflicted tissue damage, which leads to changes in plant chemistry, followed by the production of signaling molecules that trigger a general stress response, similar to the basal plant defense to phytopathogens. While general or basal defense responses are involved in signaling in both aphid-resistant and aphid-susceptible plants, gene-for-gene interactions are specific for aphidresistant plants only.

The activation of signaling pathways in response to phloem-feeding aphids alters gene expression, which in turn leads to changes in the molecular composition inside the cell. DNA sequencing analyses have indicated that encoded proteins function in direct defense, defense signaling, oxidative burst, secondary metabolism, cell maintenance and photosynthesis (Zhu-Salzman et al. 2004). Van der Biezen and Jones (1998) reported that nucleotidebinding leucine-rich-repeat (NB-LRR) proteins provide resistance to insects, including aphids. Genes encode NB-LRR proteins that constitute the major R-protein class in gene-for-gene plant resistance. Recognition of Avr proteins from aphids by NB-LRR proteins, such as Mi- 1 from the tomato, was reported by Rossi et al. (1998). Activation of NB-LRR proteins may induce different responses depending on salicylic acid (SA) and reactive oxygen species (ROS). The recognition of aphid feeding by plant receptors, transmembrane pattern recognition receptors (PRRS) and the ensuing plant defense responses are followed by the transmission of defense response signal cascades that involve various signaling molecules. Plant signaling pathways are driven by phytohormones such as jasmonic acid (JA), salicylic acid (SA), ethylene (ET), abscisic acid (ABA), gibberellic acid (GA) and free radicals (ROS), mainly hydrogen peroxide $\left(\mathrm{H}_{2} \mathrm{O}_{2}\right)$ and nitric oxide (NO), that induce plant defenses to aphid infestation (Gao et al. 2007). These molecules can act separately or together, with antagonistic or synergistic interactions in the plant signaling network (Fig. 1).

Smith and Boyko (2007) suggested that sugars such as sucrose, glucose, fructose and trehalose also function as messengers in plant signal transduction after aphid infestation, and plant defense responses induced by aphid feeding stimulate the increased production of intercellular chitinases and $\beta$-1,3-glucanases involved in cell wall oligosaccharide release. Mutti (2006) reported that sucrose and trehalose are two sugars involved in signal transduction in plants and that trehalose is also the predominant hemolymph sugar in insects. Putative trehalase secretions are present in the salivary glands of the pea aphid and may play a crucial role in the breakdown of plant trehalose, thereby disrupting signal transduction in plants and thus allowing the aphids to feed continuously. An increasing body of evidence has recently pointed to interesting and important roles for oligosaccharides in plant defense against biotic stresses (Morkunas et al. 2005; Robert-Seilaniantz et al. 2007; Morkunas and Bednarski 2008; Moloi and van der Westhuizen 2009; Yoshioka and Shinozaki 2009; Morkunas et al. 2011). This review presents the molecular mechanisms behind plant responses to aphid feeding and the 


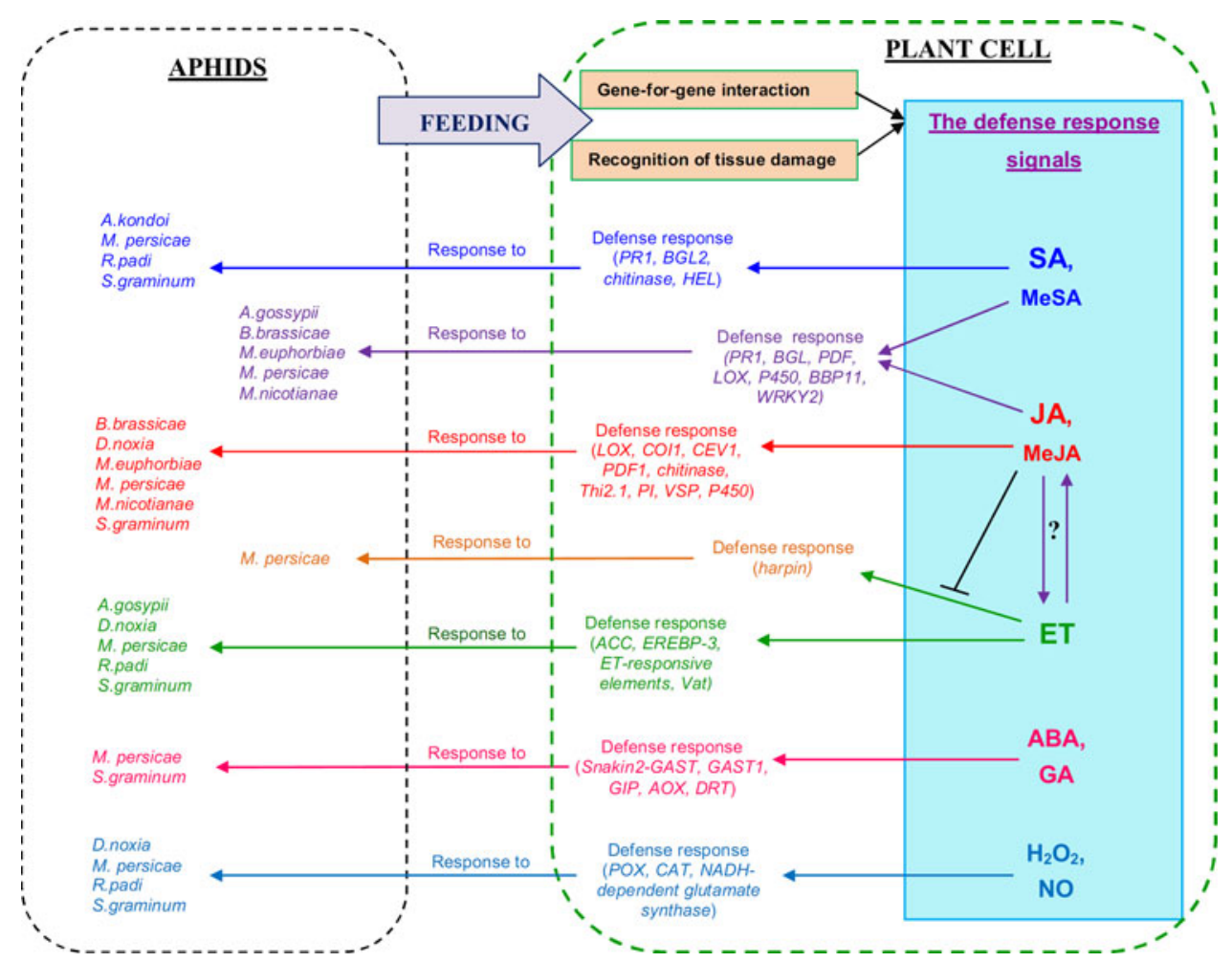

Fig. 1 A schematic illustration of plant signaling pathways involving defense responses to aphid feeding. Arrows indicate pathway activation. Positive regulatory interactions between these signaling pathways are indicated by bidirectional arrows, antagonistic interactions by lines. $S A$ salicylic acid, MeSA methyl salicylate, $J A$ jasmonic acid, MeJA methyl jasmonate, ET ethylene, $A B A$ abscisic acid, $G A$ gibberellic acid, $\mathrm{H}_{2} \mathrm{O}_{2}$ hydrogen peroxide, $\mathrm{NO}$ nitric oxide, PRI pathogenesis-related protein 1, BGL2 $\beta$-1,3-glucanase 2, $H E L$ heveinlike protein, $P D F$ plant defensin, Thi2.1, thionin 2.1; LOX

precise mode of activation of various endogenous bioactive signaling molecules. The participation of these molecules in the regulation of numerous defense genes leads to specific metabolic responses such as the activation of many proteins connected with defense, biosynthesis or the accumulation of low-molecular secondary metabolites including phytoalexins. Selected important points in signal transduction pathways were also discussed in the light of research into plant responses to aphid feeding.

\section{Jasmonic acid in plant response to aphid feeding}

Jasmonic acid (JA) and ester-methyl jasmonate (MeJA) are linoleic acid-derived cyclopentanone-based compounds and key molecules of the octadecanoid-signalling pathway (Meyer et al. 1984). The JA biosynthesis pathway with the involvement of lipoxygenase (LOX) has been studied extensively in relation to resistance to insects (Bostock 1999). The JA functions in plant defense against insects have been described in Arabidopsis and some other plants, lipoxygenase, $P 450$ cytochrome $\mathrm{P} 450, B B P 11$ Bowman-Birk protease inhibitor 11, WRKY2 transcription factor, COI1 coronatine insensitive 1, CEV1 constitutive expresser of vegetative storage protein $1, P I$ proteinase inhibitors, VSP vegetative storage protein, ACC 1-aminocyclopropane-1-carboxylate oxidase, EREBP-3 ET-responsive element binding protein 3, Vat virus aphid transmission gene, GAST1 GA-stimulated transcript, GIP GA-induced protein, $A O X$ aldehyde oxidase, $D R T$ drought-, salt- and low-temperature responsive gene, $P O X$ peroxidase, $C A T$ catalase

such as tobacco, wheat and sorghum. The importance of jasmonic acid in wound-induced defense responses has been demonstrated by the fact that the exogenous application of JA or MeJA induces these defense responses. The increased level of endogenous JA after wounding correlates with the induced defense responses and the inhibition of the JA production pathway also inhibits the induction of the defense responses. In addition, transgenic plants and mutants have been important tools in elucidating the role of jasmonic acid in signal transduction involved in direct plant defense. Besides jasmonic acid, several other related oxylipins also appear to function as signaling molecules. Examples include 12-oxophytodienoic acid (OPDA) and dinor-oxo-phytodienoic acid (DN-OPDA) (Dicke and Van Poecke 2002). Korth and Thompson (2006) revealed that JA, MeJA and its precursor, OPDA are potent inducers of proteinase inhibitors (PI), and it has been suggested that these play central roles in plant responses to herbivore attack. Monaghan et al. (2009) reported that JA and ET are integral to resistance against not only herbivores, but also necrotrophic pathogens. 
When plant cells are penetrated by aphids, the JA signal is probably transduced by the activation of receptors that bind these molecules (Turner et al. 2002). Arabidopsis defense responses are induced by both OPDA and by jasmonic acid, whereas stamen development is induced by jasmonic acid, but not by OPDA. These findings suggest that, in Arabidopsis at least, two pathways transduce secondary JA signals, one for the recognition of either OPDA or jasmonic acid for defense responses, and one for the recognition of jasmonic acid, but not OPDA, for stamen development. Several Arabidopsis mutants involved in JA signal perception and transduction response to aphid feeding have been isolated, the best characterized of which are coil (coronatine insensitive 1) and jarl (jasmonate resistant 1) (Balbi and Devoto 2008). The COI1 gene is closely related to the auxin signaling TIRl (transport inhibitor response 1) gene. AXR1 (AUXIN RESISTANT 1 ) is a positive regulator of auxin response. As a result of the similarities in the mode of action of COI1 and TIR1, it is tempting to speculate that jasmonate and auxin might use analogous signaling mechanisms sharing common components such as AXR1. The COII gene encodes a protein containing an N-terminal F-box motif. F-box proteins occur popularly in organisms in the eukaryote kingdom and function as signal receptors to regulate defense. The JARI gene exhibits similarity to the auxin-induced $G H 3$ transcriptional product from soybean, and neither protein shows homology to previously described plant receptor proteins.

Recent research in JA signaling has uncovered new elements and crucial nodes for the regulation of signaling networks in different physiological scenarios (Balbi and Devoto 2008). One such emerging signaling network, integrating different plant responses, appears to be regulated by WRKY transcription factors, at least in the context of defense. Activated JA-signaling pathways have been demonstrated to be involved in defense in the context of the JA-regulated expression of WRKY62 (via COI1-independent pathways). A study by Kuśnierczyk et al. (2008) revealed that WRKY transcription factors were induced in Arabidopsis defense responses to cabbage aphid (Brevicoryne brassicae) attack; however, WRKY62 induction was not observed.

Fujita et al. (2009) reported that a vital role in the JA-signaling pathway in Arabidopsis plants is played by the basic helix-loop-helix transcription factor ATMYC2. The transcription factor ATMYC2 positively regulates JA-mediated resistance to insect herbivory and tolerance to oxidative stress, possibly by enhancing flavonoid biosynthesis and ascorbate redox cycling, and negatively regulates tryptophan metabolism, leading to JA-dependent synthesis of defensive compounds such as indole glucosinolates (GS). JA-dependent ATMYC2 expression appears to be negatively regulated by the JA-activated MKK3MKK6 pathway, whereas an unidentified signaling pathway may be implicated in the JA-mediated positive regulation of $A T M Y C 2$ expression. Taken together, the positive and negative regulation of ATMYC2 expression might be an important mechanism underlying the JA-signaling pathway.

Mewis et al. (2005) revealed that after $24 \mathrm{~h}$ of feeding by the chewing insect $S$. exigua, and 1 week of feeding by the phloem-feeding insects $M$. persicae and $B$. brassicae, the GS levels in 4-week-old Arabidopsis plants Col wild type (Col-0) are altered, although to different extents. GS are sulfonated thioglycosides, comprising a common glycone moiety with a variable aglycone side chain, and play defensive and protective roles against pests. Additionally, an exogenous application of $25 \mathrm{mM}$ JA to Col-0 plants produced significant increases in total indolyl GS concentrations and significant increases in two aliphatic GS, but not in total aliphatic GS concentrations. All three insects elicited increases in aliphatic GS concentrations. Only the aphid B. brassicae elicited increases in individual, but not total, indolyl GS. Blocked JA signaling in coronatineinsensitive (coil) and enhanced expression of SA-signaled disease resistance in hypersensitive response-like ( $r l l)$ mutants reduces constitutive GS concentrations, while blocking SA signaling at the mediator protein npr1 mutant $(N P R)$ increases them.

In turn, Slesak et al. (2001) revealed that exogenous methyl jasmonate or jasmonic acid, synthesized in response to the wounding of plants by aphid stylets, induces the expression of genes responsible either for the synthesis of enzymes of the shikimic acid pathway, leading to the accumulation of hydroxamic acids, or to the synthesis of specific proteins, the protease inhibitors.

The other mutant cev1 (constitutive expresser of vegetative storage protein 1) also displays constitutive activation of defense responses against aphids. This mutant overproduces not only JA, but also OPDA (12-oxophytodienoic acid) and ET, along with the constitutive expression of the biotic stress-responsive genes VSP (vegetative storage protein), PDF1.2 (plant defensin 1.2), Thi2.1 (thionin 2.1) and chitinase B (Ellis et al. 2002). It has been found that CEVI encodes cellulose synthase CeSA3, providing a link between cell wall signaling and JA-, ET-regulated defense responses. The constitutive activation of JA signaling in the cev1 mutant correlates with an enhanced resistance to $M$. persicae. Development of the M. persicae population is greatly reduced on Arabidopsis cev1 mutants over-expressing JA and ET, and the high constitutive expression of PDF1.2 mRNA in cev1 plants is slightly reduced in leaves colonized by aphids.

Analyses of JA mutants and transgenic plants have mostly focused on altered JA-inducible gene expression 
and defense responses, as indicated above. Genes putatively involved in JA synthesis and JA-mediated defense responses (e.g. OPDA-10,11-reductase, LOX, and cytochrome P450) are activated by aphid feeding on different plants (McConn et al. 1997). LOX, the key enzyme in the JA biosynthesis pathway, has been studied in many species of plants in response to aphid feeding. For example, transcripts encoding LOX genes are strongly induced by feeding of the potato aphid (Macrosiphum euphorbiae) on tomato (Solanum lycopersicum) foliage (Fidantsef et al. 1999), and M. persicae infestation on Arabidopsis leaves (Moran and Thompson 2001). Expression of LOX and other protein transcripts is also increased in the defense response of coyote tobacco (Nicotiana attenuata) plants to tobacco aphid (Myzus nicotianae) feeding (Voelckel et al. 2004), or in aphid-resistant plants, such as wheat and sorghum, to the Russian wheat aphid (Diuraphis noxia) and the greenbug aphid (Schizaphis graminum) (Park et al. 2006; Boyko et al. 2006). In tomato plants, after Macrosiphium euphorbiae/Myzus persicae attack, the amount of LOX is strongly induced. Similarly, though to a lesser degree, signatures of JA/ET signaling ( $P R, P D F 1.2$ and LOX2) were found in Arabidopsis leaves after green peach aphid (M. persicae) feeding (Moran and Thompson 2001). Another comprehensive array-analysis, used to compare transcriptional responses in Sorghum bicolor plants elicited by $S$. graminum, showed that JA-regulated genes ( $L O X$, cytochrome $P 450$, dhurrinase) were only marginally and transiently induced by the aphid (Zhu-Salzman et al. 2004). Additionally, a similar study conducted recently showed that greenbug aphid infestation not only induces six $L O X$ genes and other genes involved in JA biosynthesis, but also activates the expression of proteinase inhibitor $(P I)$ and vegetative storage protein (VSP) genes (Gao et al. 2007). According to Gao et al. (2007) in Medicago truncatula the octadecanoid pathway was induced exclusively in resistant plants following Acyrthosiphon kondoi (bluegreen aphid) infestation. Treatment of susceptible plants with methyl jasmonate reduces bluegreen aphid infestation, but not to the same levels as in resistant lines. Together, these results strongly suggest that the octadecanoid pathway is important for this naturally derived aphid resistance trait. Other studies have shown that pretreatment with MeJA reduces aphid colonization of susceptible tomato, whereas JA treatment had no effect on aphid resistance in tomato plants expressing the $M i$ gene (Cooper and Goggin 2005). JA treatment also reduced aphid reproduction in sorghum, although the transcript levels of JA-responsive genes were not altered following aphid infestation (Zhu-Salzman et al. 2004). In addition, lower green peach aphid reproduction was observed on susceptible Arabidopsis plants when JA signaling was constitutively increased by a mutation of the CEVl gene, although the precise role of JA in reducing aphid performance needs further studies given the pleiomorphic phenotypes associated with this mutant (Ellis et al. 2002). Precursors of JA also appear to function in the protection of aphid-resistant sorghum and wheat plant tissues against aphid herbivory, but they are also involved in the defense response of aphid-susceptible Arabidopsis and Nicotiana (Smith and Boyko 2007).

\section{Salicylic acid in plant response to aphid feeding}

Whereas JA and ET are particularly well known as positive regulators of plant responses to herbivores and necrotrophic pathogens, salicylic acid (SA) has long been associated with resistance to biotrophic pathogens (Monaghan et al. 2009). Biosynthesized in the shikimate pathway, SA is known to promote the development of systemic acquired resistance (SAR), a broad-range resistance against pathogens, and is crucial for localized plant tissue hypersensitive responses (Walling 2000). SA-dependent responses following infection by bacteria, fungi and other pathogens use SA and its methyl conjugate, MeSA to stimulate the expression of defense response genes, including pathogenesis-related $(P R)$ proteins or $P R$ genes with apoplastic localization (Moran and Thompson 2001). SA accumulation is associated with a buildup of reactive oxygen species that cause significant changes in cellular redox levels. These redox changes are sensed in the cytosol by the key defense protein NPR1 (NON-EXPRESSOR OF PR GENES1; Monaghan et al. 2009). Kawano et al. (2004) reported that putative SA receptors are SA binding proteins (SABPs). SABPs proteins were isolated from tobacco, the first was shown to be catalase (Chen et al. 1993; Conrath et al. 1995), the second was proposed as a lipase belonging to the $\alpha / \beta$ fold hydroxylase super family (Du and Klessig 1997) and a third was identified as a chloroplast-targeted carbonic anhydrase (Slaymaker et al. 2002). However, protein SABP2 shows a much greater affinity to SA when compared to catalase (Du and Klessig 1997). In turn, Vasyukova and Ozeretskovskaya (2007) revealed that not only catalases, but also ascorbate peroxidases, aconitases, and certain MAP kinases are viewed as SA receptors.

The role of SA in response to aphid feeding has been observed in many plant species such as Triticum aestivum, Arabidopsis thaliana, barley, Medicago truncatula and Phaseolus lunatus. For example, induction of SA in resistant wheat (Triticum aestivum) indicates a possible involvement of this molecule in the resistance mechanism of wheat against the Russian wheat aphid (Diuraphis noxia). Activities of catalase and peroxidase (markers of resistance response) in the resistant $T$. aestivum were higher than in the susceptible variety. Aphid infestation had an inhibiting effect on catalase activity in both resistant and 
susceptible plants, which may be a consequence of SA binding to catalase and inhibiting its activity. Thus, an increased SA level may be a critical step in the signaling of downstream defense responses (Mohase and van der Westhuizen 2002).

Kuśnierczyk et al. (2008) revealed that a wide range of defense responses in Arabidopsis thaliana to attack by Brevicoryne brassicae is dependent on SA signaling. They observed the induction of the following transcription factors involved in plant resistance: WRKY15, WRKY26, WRKY30, WRKY38, WRKY46, WRKY50, WRKY51 and WRKY54. Transcription factor WRKY54 was shown to be a factor under the control of SA (via NPR1-dependent pathways) during defense response by Balbi and Devoto (2008) in a model for a regulatory network integrating WRKY transcription factors. Genes involved in SA synthesis (ICS1 and ICS2), the induction of the SA signaling pathway (EDS1, EDS5 and PAD4) and stress-responsive SA-dependent genes (PR1, PR2, PR4, PR5, NIMIN-1, NIMIN-2 and SABP2-like) were up-regulated, as reported by Kuśnierczyk et al. (2008). Some of these genes were induced already at $6 \mathrm{~h}$ after infestation, indicating an early recognition of $B$. brassicae attack. Genes coding for PR proteins were significantly more highly induced at later time points, suggesting that a time period between 12 and $24 \mathrm{~h}$ is required to develop SA-related responses. Additionally, a substantial accumulation of phytoalexin camalexin was observed 48 and $72 \mathrm{~h}$ after infestation.

Chaman et al. (2003) noted SA accumulation occurring in two barley varieties, UNA-80 and LM-109, in response to the damage caused by Schizaphis graminum; however, the level of free SA in UNA-80 was higher than in LM-109 after infestation. The smaller reproduction index of aphids in variety LM-109 is probably due to the greater presence of SA conjugates, phenolic compounds and other defensive characteristics than may be observed in UNA-80.

Numerous researchers have shown that activation of the SA pathway may be a general mechanism of antibiosis or aphid repellence in resistant hosts, with a limited effectiveness in susceptible ones. Aphid-induced methyl salicylate (MeSA) is a strong aphid repellent that may deter aphids from settling on plants with already high aphid densities (Bernasconi et al. 1998; Hardie et al. 1994; Preston et al. 1999; Shulaev et al. 1997). Gao et al. (2007) examined a phenylalanine ammonia lyase $(P A L)$ gene involved in the phenylpropanoid pathway, which leads to the biosynthesis of SA, flavonoids, and isoflavonoids. The $P A L$ gene transcript levels were induced in both susceptible and resistant plants of Medicago truncatula following Acyrthosiphon kondoi (bluegreen aphid) infestation. Similar results were found in other susceptible plants following aphid attack (Moran and Thompson 2001; Moran et al. 2002; de Ilarduya et al. 2003; Heidel and Baldwin 2004;
Voelckel et al. 2004; Zhu-Salzman et al. 2004). Park et al. (2006) demonstrated higher levels of SA-responsive gene transcripts in susceptible, rather than resistant, sorghum plants following greenbug infestation. Gao et al. (2007), however, found interesting differences in the timing of interactions between susceptible and resistant $M$. truncatula and the bluegreen aphid that could be important, with the induction of all the three SA-responsive genes, being earlier in Jester (a BGA-resistant genotype) than A17 (a susceptible genotype) following infestation. De Ilarduya et al. (2003) also found that, in tomato infested with potato aphids, an earlier and stronger induction of SA-responsive genes occurred in a resistant cultivar carrying the $\mathrm{Mi}-1.2$ gene than in the susceptible parent. Moreover, Li et al. (2006) used the SA-metabolizing NahG as a transgene in a $\mathrm{Mi}-1.2$ background to demonstrate that $\mathrm{SA}$ is essential for potato aphid resistance.

Various SA-defense-related genes have been demonstrated to be involved in plant responses to herbivores, including aphids. As mentioned above, aphid feeding has been shown to induce the activity of several $P R$ proteins, such as peroxidases $(P O X)$ or $P R$ genes in plants (Fidantsef et al. 1999). Studies in Arabidopsis thaliana provided basic but important insights into the mechanism of SA signaling in the defense of plants from aphid attack. The NPRI regulatory gene conditions SA-responsiveness in Arabidopsis, raising the possibility that an alteration of this gene, or others involved in SAR, could influence plant responses to aphid herbivory (Cao et al. 1994). The NPRl protein is a vital component of SA signaling in Arabidopsis because NPRl supplies an important link between different defense mechanisms, for example, the action of the NPRl gene was necessary for Arabidopsis to induce $P R$ gene responses to aphids, or the enhanced PDF1.2 induction in the nprl mutant (Moran and Thompson 2001). It is of interest in this plant that aphid feeding induced the transcription of two genes associated with SA-dependent responses to pathogens, namely $P R-1$ and BGL2 ( $\beta$-1,3-glucanase 2). Expression of $P R-1$ and $B G L 2$ mRNA was induced by the green peach aphid $M$. persicae in nprl mutant plants, which are deficient in SA signaling. Application of the SA analog benzothiadiazole leads to a decrease in aphid reproduction on the leaves of both wild-type plants and mutant plants. Along with the involvement of defense genes, all SA-responsive transcripts studied in the legume Medicago truncatula (BGL, PR5, and PR10) were activated by bluegreen aphid (Acyrthosiphon kondoi) infestation in both resistant and susceptible plants, although there were some differences in the magnitude and kinetics of the induction (Gao et al. 2007). To defend itself against greenbug aphid (Schizaphis graminum) feeding, sorghum increases transcript abundance of genes associated with the SA defense signaling pathway, including $P R$ genes such as 
$B G L 2$, chitinases, and HEL (a hevein-like protein) (ZhuSalzman et al. 2004). Similarly, in tomato plants containing the $M i-1$ gene, the systemic expression of $P R-1$ and $G l u B$ products was detected in both compatible and incompatible interactions after potato and green peach aphid feeding (de Ilarduya et al. 2003).

Aphid infestation not only activated, but also downregulated the expression of some SA-defense-related genes, such as $P R$ genes, in the interaction between $S$. graminum and an aphid-resistant sorghum genotype (Park et al. 2006). Likewise, it did not up-regulate expression in interactions between $D$. noxia and an aphid-resistant wheat genotype (Boyko et al. 2006). Otherwise, wheat $P R$ proteins are induced to high levels both in resistant and susceptible genotypes; however, the specific resistance mechanisms of these responses remain unknown at the time of writing (van der Westhuizen et al. 1998).

A remarkable SA derivative compound emitted by several plant species in response to herbivores, MeSA, activates the SA-dependent defense-signaling pathway and also induces $P R$ gene expression (Shulaev et al. 1997). This compound acts as a defense factor in Lima bean (Phaseolus lunatus) leaves infested by the two-spotted spider mite (Tetranychus urticae) (Ozawa et al. 2000). MeSA increases volatiles that are qualitatively and quantitatively similar to T. urticae-induced volatiles. In addition, T. urticae damage results in the expression of acidic and basic $P R$ genes that are activated under MeSA effects. Similarly, MeSA is released in the SA-related signaling pathway of the broad bean (Vicia faba) to repel the black bean aphid (Aphis fabae) (Hardie et al. 1994). In fields treated with MeSA, colonization by the aphids Rhopalosiphum padi, Sitobion avenae and Metopolophium dirhodum on summer host plants was significantly reduced (Pettersson et al. 1994). MeSA significantly decreased colonization of field grown cereals by $R$. padi and populations of $\mathrm{S}$. avenae and $M$. dirhodum were significantly smaller on treated plots.

Together, these results strongly suggest that the SA-related signaling pathway is involved in plant responses to herbivores and that the novel defense role of SA and its conjugate could be elicited by phloem-feeding insects.

\section{Ethylene in plant response to aphid feeding}

The induction of ethylene emission in response to herbivory, wounding or elicitors has been reported for several plants and the application of systemin or JA in tomato cell suspensions also enhanced the production of this plant hormone. In the tomato, both genes encoding enzymes involved in ethylene production from $S$-adenosyl-methionine, 1-aminocyclopropane-1-carboxylate synthase (ACS) and 1-aminocyclopropane-1-carboxylate oxidase (ACO), were also up-regulated by wounding (Dicke and Van Poecke 2002). Gao et al. (2007) also reported that genes involved in the ethylene pathway, i.e. ACC oxidase or as named above ACO, ERF1 (ethylene responsive factor), HEL (hevein-like protein) were induced in both the susceptible and resistant plants of Medicago truncatula following Acyrthosiphon kondoi (bluegreen aphid) infestation.

As is the case with wounding, an exogenous application of ethylene induces the production of enzymes, such as phenylalanine ammonialyase (PAL), chalcone synthase (CHS), and hydroxyproline-rich glycoproteins (HPRG, is involved in cell wall strengthening). However, for HPRG it was shown that different isoforms are induced by wounding in comparison to ethylene application. In most plants ethylene induces the synthesis of compounds that crosslink with cell wall polymers, thus reinforcing the cell wall structure and reducing injury caused by insect attack (Dicke and Van Poecke 2002). Additionally, Guy et al. (2001) revealed that the genes encoding basic isoforms of PR proteins are generally induced by both ethylene application and wounding, which suggests that ethylene may be the mechanism for their activation by wounding.

Ethylene is perceived by a family of membrane-associated receptors, including ETR1/ETR2, ETHYLENE RESPONSE SENSOR1 (ERS1/ERS2) and EIN4 in Arabidopsis (Chang and Stadler 2001). Ethylene binds to its receptors via a copper co-factor, which is probably delivered by the copper transporter RAN1. The receptor family can be divided into two subfamilies. Genetic and biochemical studies have revealed that the ethylene receptors function as negative regulators of ethylene responses and ethylene binding inactivates them (Guo and Ecker 2004). Recently, it was found that ethylene perception and signaling occur at the endoplasmic reticulum (ER) (Chen et al. 2002). The cloning and characterization of numerous ETYLENE INSENSITIVE3 (EIN3/EIN3-like (EIL) transcription factors from many plant species, and the integration of the ethylene and jasmonate response pathway via the ETHYLENE RESPONSE FACTOR (ERF) family of transcription factors, have also been reported (Chao et al. 1997). Highly up-regulated ET-responsive transcription factors 11 (ERF11) and ERF1-like has been observed in Arabidopsis during B. brassicae attack.

Previous reports indicated that aphid infestation induced a greater evolution of ET in susceptible rather than resistant cultivars of alfalfa, wheat and barley (Dillwith et al. 1991; Anderson and Peters 1994; Miller et al. 1994). However, physiological and molecular responses to infestation will depend on several factors such as plant cultivar, plant age, degree of infestation, aphid species and biotype, and infestation time. Anderson and Peters (1994) found that different combinations of wheat genotype-greenbug biotypes produced different amounts of ethylene. 
In contrast, Argandona et al. (2001) when investigating whether ethylene is involved in the oxidative and defensive responses of barley to the aphids Schizaphis graminum and Rhopalophum padi, observed that under aphid infestation the production of ethylene was higher in cultivar Frontera, which was also more tolerant to aphids, than in Aramir, a more aphid-susceptible cultivar. Ethylene production also increases with the degree of infestation and Schizaphis graminum aphids induced more ethylene evolution than Rhopalophum padi. Infestation with $S$. graminum increased hydrogen peroxide content as well as total soluble peroxidase activity in cv. Frontera, with a maximum level of $\mathrm{H}_{2} \mathrm{O}_{2}$ observed after 20 min of infestation and a maximum soluble peroxidase activity after $30 \mathrm{~min}$ of infestation. When non-infested barley seedlings from cv. Frontera were exposed to ethylene, an increase in hydrogen peroxide and in total peroxidase activity was detected at levels similar to those of infested plants of cv. Frontera. Ethylene also increased the activity of cell wall-bound peroxidase types (both ionic and covalent binding), which is comparable with infestation.

A partial activation of groups of Arabidopsis genes functioning in oxidative stress, calcium-dependent signaling, $P R$ responses, and defense compound synthesis was noted in response to $M$. persicae feeding. At the same time induction was observed of a gene encoding an ethylene biosynthesis gene, 1-aminocyclopropane-1-carboxylic acid (ACC) oxidase $(A C O 1)$, while a gene encoding an ACC synthase (ACC2) showed no change (Moran et al. 2002). In contrast to Arabidopsis, in aphid-susceptible celery, ET-responsive EREBP-3 and ET-responsive elements (but not any ACC genes) are up-regulated by $M$. persicae feeding (Divol et al. 2005).

In a recent study, the expression of key ET-associated genes was investigated in both resistant and susceptible interactions in two model systems, namely the tomatoMi-Macrosiphum euphorbiae system and the melon-virus aphid transmission (Vat) gene-Aphis gossypii system (Anstead et al. 2010). When compared with the control plants, plants infested with aphids showed marked differences in gene expression. ET signaling pathway genes and downstream response genes were highly up-regulated in the resistant interaction between $\mathrm{A}$. gossypii and $\mathrm{Vat}^{+}$ plants, indicating that ET may play a role in Vat-mediated plant resistance. The $M i$ gene is not directly involved with the plant defense response to $M$. euphorbiae feeding. The $M i-1$ gene, in tomato resistance to $M$. euphorbiae, expressed similar effects (Mantelin et al. 2009). During the early stages of both compatible and incompatible interactions, aphid feeding induces the expression of ET biosynthetic genes. However, impairing ET signaling or biosynthesis did not compromise $\mathrm{Mi}$-1-mediated resistance, but did decrease susceptibility to potato aphids in a compatible host. ET may not play a significant role in Mi-1-mediated resistance to M. euphorbiae in the tomato, but modulates the host basal defense, enhancing its susceptibility to the aphid.

\section{ABA and GA act as signals in plant defense response to aphid feeding}

In contrast to the above-mentioned plant hormones, the role of other hormones, such as abscisic acid (ABA) and gibberellic acid (GA), has been presented to a minor degree in the context of plant resistance. An increasing body of evidence has recently pointed to interesting and important roles for these hormones in plant defense against biotic stress (Robert-Seilaniantz et al. 2007). Flors et al. (2009) revealed the role of $\mathrm{ABA}$ in basal and induced resistance and in priming phenomena against biotic stress. Genetic approaches have characterized several downstream components of ABA signaling, but a receptor for $\mathrm{ABA}$ has remained elusive. Recently, Nishimura et al. (2009) reported that structures of pyrabactin resistance 1 (PYR1), a prototypical PYR/PYR1-like (PYL)/regulatory component of the ABA receptor (RCAR) protein, functions in early ABA signaling. Previously, Razem et al. (2006) provided evidence that the RNA-binding protein FCA may be an ABA receptor involved in a physiological process, although not in plant defense reactions.

ABA and GA were earlier presented as having no effects on aphid feeding (Miller et al. 1994). In extensive experiments on barley, ABA and GA, applied to uninfested leaves, failed to produce the $\mathrm{D}$. noxia induced damage symptoms of rolling or streaking. Furthermore, the application of these regulators to plants infested by $D$. noxia had no effect on the development of aphid-induced damage.

Recently, ABA has been shown to play an important role during plant-insect interactions (Flors et al. 2009). Investigations into the relationship between plant stress and resistance to herbivory have led to the hypothesis that herbivores should show improved performance on mildly stressed plants (White 1974). ABA may be involved in defense against insects after aphid infestation of celery plants (aphid susceptible) or sorghum and wheat (aphid resistant). During these interactions several genes, that share sequences with those involved in the biosynthesis of, or that are activated by, ABA, are upregulated (Park et al. 2006; Boyko et al. 2006). For example, the gene encoding ABA-water stress-ripening-induced protein (ASR) in sorghum showed a differential regulation in response to greenbugs (Park et al. 2006). Induction of the ASR gene for the protection of plant DNA under water-stressed conditions is known to be controlled by the phytohormone ABA (Riccardi et al. 1998). Moreover, as it was noted by Park 
et al. (2006), other genes, such as those encoding starch synthase (SS), induced control from the 12th hour of greenbug infestation, and gradually increased induction as an extension of infestation. In turn, the GA-induced protein (GIP) and seed maturation protein were either up or downregulated by greenbug feeding. The GIP gene was induced from $72 \mathrm{~h}$ of greenbug infestation. Thus, it is plausible that regulators such as abscisic acid and gibberellic acid were involved in the mediation of defense responses against greenbug phloem-feeding in sorghum.

Conversely, Voelckel et al. (2004) found that a sequence encoding 3-hydroxy-3-methyl glutaryl coenzyme A reductase, which is involved in ABA biosynthesis, is downregulated in Nicotiana attenuate infested by Myzus nicotianae. In Schizaphis graminum-resistant sorghum plants, Park et al. (2006) identified several highly upregulated genes under ABA control that are involved in cell wall strengthening (Smith and Boyko 2007). Additionally, Zhu-Salzman et al. (2004) reported that, in sorghum, two genes, the aldehyde oxidase $(A O X)$ gene and the drought, salt, and low-temperature responsive $(D R T)$ gene, which are known to be regulated by $\mathrm{ABA}$, were profiled in response to greenbugs. However, as with plant reactions toward pathogens, ABA also has various regulatory functions against insects. ABA levels are not altered during corn infestation by the ear worm caterpillar; however, in tomatoes ABA levels increase significantly after wounding (Schmelz et al. 2003).

ABA has also been suggested to be a factor in the mix of signals that modulate wound-induced gene activation in Solanaceous plants (Bostock 1999). In ABA-deficient tomato and potato mutants, the wound and systemininduced levels of proteinase inhibitor (PI) II in the leaves are markedly reduced in comparison to wild-type plants. ABA is known to operate upstream of the octadecanoid pathway, possibly by affecting the release of linolenic acid, a JA precursor. ABA modulation of wound-responsive genes in the potato is complicated and provides evidence for a JA-independent pathway for ABA induction of wound-inducible genes in certain organs.

Under conditions of water stress, leaf moisture content surrounding stomata is reduced. This situation can alter the leaf environment for insects. Low humidity reduces hatching of lepidopteran eggs (Godfrey and Holtzer 1991), spider mite population growth (Perring et al. 1984), and the growth of many species of insect larvae (Mattson and Scriber 1987). Consequently, ABA-deficient tomato plants have a reduced resistance to Spodoptera exigua (Thaler and Bostock 2004). These results show that ABA differentially regulates pathogenic or insect responses and is highly dependent on the challenge and plant species.

It has previously been considered that GA acts as a plasma membrane-bound receptor and plays a role in plant defense response signaling by regulating $\beta$-1,3-glucanase release from the aleurone cells of cereal grains (Matsuoka 2003). Ueguchi-Tanaka et al. (2007) postulated that plants have two types of GA receptors, including soluble and membrane-bound forms. Recently, it was determined that the rice GIBBERELLIN INSENSITIVE DWARF 1 (GIDI) gene encodes an unknown protein, similar to the hormonesensitive lipases, that has high affinity for biologically active GAs. GA signaling is now understood to hinge on DELLA proteins, which also promote transcription of the GA receptor, GID1 and indirectly regulate GA biosynthesis genes enhancing GA responsiveness and feedback control. In several recent studies, genes putatively involved in GA-associated signaling (Snakin2-GAST, GAST1) have been shown to up-regulate in aphid-infested leaf tissues of M. persicae-susceptible celery (Divol et al. 2005). Similar results were noted by Park et al. (2006), as previously mentioned, when genes encoding GA-induced protein $(G I P)$ was induced in sorghum infested with the greenbug aphid.

\section{ROS and NO involved in plant response to aphid feeding}

Reactive oxygen species (ROS), mainly hydrogen peroxide, $\mathrm{H}_{2} \mathrm{O}_{2}$, are molecules of defense signaling pathways with known involvement in the activation of plant response to aphid attack (de Ilarduya et al. 2003). $\mathrm{H}_{2} \mathrm{O}_{2}$ is a relatively stable ROS. Being only mildly reactive and electrically neutral, $\mathrm{H}_{2} \mathrm{O}_{2}$ is able to pass through cell membranes and reach cell locations remote from the site of its formation. Plant cells produce $\mathrm{H}_{2} \mathrm{O}_{2}$ in response to various biotic factors (Wojtaszek 1997), thus $\mathrm{H}_{2} \mathrm{O}_{2}$ production is a general response of plants to stress conditions and not specific to plants infested by aphids. The $\mathrm{H}_{2} \mathrm{O}_{2}$ released by the plant in response to infestation by aphids is of significant importance and concerns its involvement in signal transmission, since it is easily transported over considerable distances. $\mathrm{H}_{2} \mathrm{O}_{2}$ activates defense genes. For example, peroxidases are involved in the stimulation of cell wall reorganization and induce cross-linking of proline-rich plant cell wall proteins. Additionally, a high $\mathrm{H}_{2} \mathrm{O}_{2}$ level could have a toxic action against aphids, causing damage.

Results reported by Kuśnierczyk et al. (2008) indicated the involvement of reactive oxygen species (ROS) and calcium in early signaling in Arabidopsis thaliana after infestation by aphids, Brevicoryne brassicae. Hydrogen peroxide activates the protein phosphorylation cascade, which modulates gene expression in response to external stimuli. This cascade involves subsequent phosphorylation events of MAPK, the last of which results in translocation to the nucleus and activation of transcription factors. The 
expression of five genes coding for MAPKs $(M K K 1, M K K 2$, $M K K 4, M K K 9$ and $M K K 11$ ) was positively regulated in an experiment conducted by Kuśnierczyk et al., indicating the possible activation of this signal transduction cascade in response to B. brassicae attack. Expression levels of several genes associated with oxidative stress, especially ROS scavengers, were changed in response to B. brassicae attack, suggesting that the redox status in the attacked plants had been disturbed. Transcript levels of many genes coding for proteins contributing to ROS detoxification were accumulating by $6 \mathrm{hpi}$, and reached maximum expression at $24 \mathrm{hpi}$. Among the up-regulated genes, the following groups were found: ascorbate reductases (MDAR 1 and MDAR 4); L-ascorbate oxidase; RESPONSIVE TO HIGH LIGHT 41 (RHL41), which is required for the expression of cytosolic ascorbate peroxidase during oxidative stress; copper homeostasis factor $(\mathrm{CCH})$; blue copper protein precursor $(A t B C B)$; four glutaredoxin family proteins; thioredoxin (TRX5); glutathione $S$-transferases (induced at 6 hpi: ATGST6, ATGST7 and ATGST10, and induced strongly at 48 hpi: ATGSTU3, ATGSTU10, ATGSTU11 and At5g02780); glutathione $S$-conjugate transporters (MRP3 and MRP4); and peroxidase precursors (Atperox P34, P37, $P 50, P 52$ and $P 71)$. Genes coding for hydrogen peroxide $\left(\mathrm{H}_{2} \mathrm{O}_{2}\right)$ generating copper amine oxidases (At4g12290 and At1g62810) and NADPH oxidase (RBOHD) were moderately induced at 24 and 48 hpi.

The involvement of $\mathrm{H}_{2} \mathrm{O}_{2}$ in the stimulation of cell wall reorganization, with the participation of peroxidases, in barley after infestation with Schizaphis graminum and Rhopalophum padi aphids was shown by Argandona et al. (2001). In infested barley plants the maximum level of $\mathrm{H}_{2} \mathrm{O}_{2}$ found was about $10 \mathrm{~min}$ before the maximum accumulation of soluble peroxidase activity. This suggests that the accumulation of soluble peroxidase activity is a consequence of the $\mathrm{H}_{2} \mathrm{O}_{2}$ burst and appears to indicate that the accumulation of $\mathrm{H}_{2} \mathrm{O}_{2}$ could mark the beginning of a cascade of events that triggers physiological and molecular plant responses intended to prevent or minimize insect attack. Moloi and van der Westhuizen (2006) revealed that the induced intercellular peroxidase activity, combined with an elevated $\mathrm{H}_{2} \mathrm{O}_{2}$ level, could be involved in cell wall strengthening. Higher $\mathrm{H}_{2} \mathrm{O}_{2}$ generation as a result of strong NADPH oxidase activity in resistant wheat cultivars rather than susceptible ones, may be involved in resistant response to infestation with the Russian wheat aphid (RWA) because $\mathrm{H}_{2} \mathrm{O}_{2}$ acts as a signal for the activation of downstream defense enzymes such as intracellular $\beta$-1,3glucanase and peroxidase.

Additionally, genes involved in oxidative signal transduction through the control of cellular hydrogen peroxide concentration, such as peroxidase (POX), NADH-dependent glutamate synthase, catalase (CAT), and the mitochondrial
ATP/ADP carrier protein, are up-regulated in aphid-infested, resistant wheat plants (Boyko et al. 2006) and in $M$. persicae-susceptible celery plants (Divol et al. 2005).

In contrast to the above, aphid feeding down-regulated several $\mathrm{H}_{2} \mathrm{O}_{2}$ concentration-dependent genes, for example, $P O X$ and $\mathrm{Fe}$-SOD (Fe-superoxide dismutase) in aphidsusceptible Arabidopsis foliage (Moran et al. 2002), or the cystein protein inhibitor in aphid-resistant sorghum leaves (Park et al. 2006). It has been suggested that down-regulation of enzyme catalase after aphid feeding may allow plants to increase $\mathrm{H}_{2} \mathrm{O}_{2}$ levels that can cause damage to the aphid (Zhu-Salzman et al. 2004).

Moreover, Park et al. (2006) reported that the up and down-regulation patterns of oxidative burst-related genes imply that ROS accumulation and detoxification occurred simultaneously during greenbug feeding. Microarray analyses between a strongly resistant sorghum phenotype (Mi) and a high susceptibility phenotype (Ti) showed an overall down-regulation of the CAT, POX, and QR genes with a concurrent down-regulation of several defenserelated genes. The reason for the down-regulation of defense-related genes, in spite of the down-regulation of oxidative burst-related genes, remains uncertain, but we assume that an intense ROS burst occurred in Ti during the early stages of greenbug feeding. Therefore, levels of ROS remained high enough to induce defense-related genes prior to harvesting of the Ti seedlings, even though scavenging of ROS had already begun. Strikingly, defenserelated genes were confirmed as being up-regulated in both $\mathrm{Mi}$ and Ti. The question remained; what factors caused Mi to possess a strong resistant phenotype to the greenbug, in comparison to the high susceptibility of Ti. Considering the results from both microarray analyses, reinforcement of cell walls presumably played a crucial part in conferring resistance to greenbugs in the M627 line.

Miles and Oertli (1993) suggested that a redox system controls oxidation rates during the responses of plants to attack by sucking insects, that soluble antioxidants, such as ascorbate and glutathione, enhance the effectiveness of the plant's defensive system, and that oxidizing enzymes in the saliva of aphids serve to counter it. Changes in the redox system of plant cells in response to sucking insects, such as aphids, caused mobilization and oxidization of phenolic compounds. The initial phenolic monomers, and especially monomeric $o$-quinones, many of which give rise to oxidation, are generally deterrent to insects.

Nitric oxide (NO) is known to increase levels, often with ROS, after pathogen attack. These molecules promote the plant hypersensitive response, stimulate SA biosynthesis, and induce some defense response genes (Walling 2000). The basic involvement of NO in the plant-aphid interaction has been mentioned in only one report on defense against the Russian wheat aphid (Diuraphis noxia) feeding on 
wheat (Triticum aestivum) (Moloi and van der Westhuizen 2009). In two T. aestivum varieties, D. noxia, feeding selectively, induced early production of NO to higher levels in resistant plants than in susceptible ones. During the aphid resistance responses, NO seems to act upstream of SA (another important signal molecule) or interact with ROS when the peroxynitrite $\left(\mathrm{ONOO}^{-}\right)$radical is found to be induced to higher levels in infested resistant plants. Other results from in vitro and in vivo studies denoted that NO could be a signal molecule in the resistant responses of wheat to D. noxia; however, the NO-related defense mechanism is not clear yet. Further research to elucidate the signal role played by NO in aphid-plant interactions still needs to be conducted.

\section{Cross-talk between signaling pathways in plant response to aphid feeding}

To defend themselves against aphids plants develop efficacious defense systems via the cross-talk amongst endogenous signal molecules, such as phytohormones including salicylic acid (SA), jasmonic acid (JA), ethylene (ET), abscisic acid (ABA), gibberellic acid (GA) and free radicals such as hydrogen peroxide $\left(\mathrm{H}_{2} \mathrm{O}_{2}\right)$ and nitric oxide (NO). Signaling pathways do not function independently, but are involved in a complex network, in which different pathways influence each other through positive and negative regulatory interactions. Cross-talk between signaling pathways may allow plants to choose an optimum defense strategy, depending on the type of herbivore feeding stimuli signaling the attack. Cross-talk between signal transduction pathways plays an important role in fine-tuning complex defense responses.

As shown by Dicke and Van Poecke (2002), the emerging picture of signal transduction in direct defense is that different signal transduction pathways interact. For example, SA blocks the biosynthesis of JA and the subsequent induction of gene expression, and consequently affects the defense of plants against herbivores (Thaler et al. 1999). For instance, treatment of plants with an SA mimic (benzothiodiazole-7-carbothioic acid $S$-methyl ester, BTH) alleviates the effect of JA treatment of tomato plants on the induction of polyphenol oxidase activity and herbivory. Conversely, JA can inhibit the effect of SA or the synthetic mimic BTH. Additionally, SA inhibits the enzymatic action of $13 S$-hydroperoxide dehydrogenase, leading to the blockage of conversion from $13 S$-hydroperoxylinolenic acid to 12-oxo-phytodienoic acid (OPDA), which is a precursor of JA biosynthesis (Pena-Cortes et al. 1993). Inhibition of proteinase inhibitors elicited by JA and MeJA occurs after SA and acetyl-SA treatment (Doares et al. 1995).
In the light of antagonistic cross-talk between the SA and JA-signaling pathways, Kuśnierczyk et al. (2008) hypothesized that Brevicoryne brassicae aphids can manipulate plant-induced resistance and are able to suppress effective JA defenses by the induction of the less efficient SA signaling-based responses. This regulatory mechanism seems to be activated in Arabidopsis after $6 \mathrm{~h}$ of B. brassicae attack. The early induction of genes coding for JAZ proteins during $B$. brassicae attack could explain the negative feedback loop which causes a slight regression of JA-associated responses at $12 \mathrm{~h}$, and the observed downregulation of the JA-inducible VSP1 and VSP2 transcripts, together with a slight decrease in the induction of PDF1 gene over time. Comparable models were proposed for plant-aphid interactions by Zhu-Salzman et al. (2005) and by De Vos et al. (2007), but lack experimental support.

Similarly, Giordanengo et al. (2010) reported that aphids such as S. graminum, Macrosiphum euphorbiae and $M$. persicae strongly induced up-regulation of the SA-dependent pathway and reduced the expression of JA-dependent genes. Apparently, aphids inhibit an efficient plant defense conferred by JA-regulated genes, while allowing the SA-regulated pathway to propagate. This could be a decoy strategy, rerouting plant response towards an inefficient defense against feeding aphids. Additionally, one hypothesis, put forward by Klessig and co-workers, suggests that plants contain regulatory switches to control the temporal expression and/or the amplitude of multiple pathways (Creelman and Mulpuri 2002).

When plants are attacked by phloem-feeding aphids JA and SA-dependent pathways coordinately regulate the expression of defense genes. An analysis of gene expression profiling upon aphid infestation has shown up-regulation of both SA and JA-responsive genes, as well as induction of other types of aphid-responsive genes. Both the SA-dependent (PR-1 and BGL- $\beta$-1,3-glucanase) and JA/ET-dependent $(P D F$ and $L O X$ ) signaling pathways were induced in Arabidopsis by feeding cabbage aphids (Brevicoryne brassicae) and cotton aphids (Aphis gossypii) (Moran and Thompson 2001). Similarly, levels of $L O X$ and $P R-1$ RNAs in infested tomato leaves increased after infestation by the potato aphid (Macrosiphum euphorbiae) and the green peach aphid (M. persicae) (Fidantsef et al. 1999).

As demonstrated by Kuśnierczyk et al. (2008), the activation of signaling pathways is integrated and temporally controlled. Although a wide range of Arabidopsis defense responses depend on SA signaling; genes coding for important enzymes of JA synthesis (PLD gamma 1, PLD gamma 2, and PLD gamma 3, LOX3-like, AOC2, OPR3) and coronatine-inducible genes (CORI3, PDF1.2, $P D F 1.2 b, P D F 1.2 c$ and $P D F 1.3)$ were generally already induced at $6 \mathrm{~h}$ of infestation. Genes coding for ZIMdomain proteins (JAZ1,JAZ5,JAZ9 and JAZ10), which are 
negative feedback regulators of jasmonate signaling, were also induced from the first time point. Also highly up-regulated were genes coding for the ET-responsive transcription factors 11 (ERF11) and ERF1-like at all time points after infestation, although the expression profiles of genes associated with ET signaling were not changed.

In potatoes fed on by $M$. euphorbiae, the expression of defense genes encoding the $P R$ proteins, LOX, PI-I and $P I-I I$ was increased in both compatible and incompatible potato-aphid feeding interactions. Although transcripts for $P R-1$ were detected earlier and accumulated to higher levels in the incompatible rather than compatible interaction, aphid feeding activities were shown to induce both JA and SA-dependent signaling pathways (de Ilarduya et al. 2003). Infestation of susceptible Arabidopsis by the green peach aphid $M$. persicae and susceptible sorghum with the greenbug aphid $S$. graminum resulted in strong up-regulation of SA responsive genes, but only a weak induction of JA-regulated genes (Moran and Thompson 2001; Zhu-Salzman et al. 2004). In defense reactions to aphid feeding, MeJA and SA coordinately induced the expression of defense genes (e.g. LOX, cytochrome P450, BBP11: Bowman-Birk protease inhibitor 11) and down-regulated other genes (e.g. chitinase 3, DRP: defense-related protein, $D B P$ : DNA binding protein).

An important role in SA and JA-mediated pathway responses to aphid feeding is played by a WRKY transcription factor family, as was mentioned in the previous section. For example, tobacco WRKY2 is found to be up-regulated by $M$. nicotianae feeding, but the signal modulation roles of WRKY2 are unknown (Voelckel et al. 2004). As mentioned in previous sections, in Arabidopsis responses to attack by Brevicoryne brassicae, the induction of transcription factors such as WRKY15, WRKY26, WRKY30, WRKY38, WRKY46, WRKY50, WRKY51 and WRKY54 may be observed (Kuśnierczyk et al. 2008). Besides this, a role in the cross-talk between SA and JA signaling has also been suggested for transcription factor WRKY70 (Bostock 1999). Expression of WRKY70 is induced by SA and repressed by JA, and the transgenic over-expression of this factor in Arabidopsis leads to the constitutive expression of PR genes. WRKY70 may serve as a point for cross-talk-an activator of SA-mediated gene expression and a repressor of JA-induced genes. However, Li et al. (2004) reported that WRKY7O is a common component in SA and JA-mediated signal pathways and modulation of WRKY7O transcript levels by constitutive over-expression is only known to increase resistance to virulent pathogens and results in the constitutive expression of $P R$ genes, though not in plant responses to aphids. A small number of reports have discussed transcription factors that function in the cross-talk between signaling pathways induced in plant responses to aphid feeding. A vital role in the JA-signaling pathway in plants can also be played by the basic helix-loop-helix transcription factor ATMYC2, which positively regulates JA-mediated resistance to insect herbivores and plays a role in SA, ET ABA, and light-signaling pathways in Arabidopsis (Fujita et al. 2009).

The molecular mechanisms underlying the cross-talk between JA and ET signaling pathways are poorly understood. In plant defense against diseases, the JA and ET pathways together converge in the transcriptional activation of ERF1 (ethylene response factor 1), which encodes a transcription factor regulating the expression of pathogen response genes (Lorenzo et al. 2003). In the case of plantinsect interaction, JA and ET-dependent pathways have frequently been demonstrated to synergistically or antagonistically induce plant defense responses to herbivory (Bostock 1999; Walling 2000; Stotz et al. 2002). For example, JA and ET showed a synergistic relationship in the production of proteinase inhibitors and defensins in Arabidopsis (Penninckx et al. 1998). This positive co-regulation, JA-ET synergism, has been observed in the induction of foliar defense responses in squash-Cucurbita moschata, in response to feeding by the silver leaf whitefly-Bemisia argentifolii (van de Ven et al. 2000). Differences in the local and systemic expression of squash genes (SLW1 and $S L W 3$ ) after whitefly feeding showed that SLW1 RNAs accumulated in response to MeJA and ET. Otherwise, resistance to M. persicae in Arabidopsis plants has been shown to develop with increased ET levels and that the expression of several genes essential for the ET signaling pathway was found to be in negative relation with JA (Dong et al. 2004). The harpin protein, which activates the ET signal in Arabidopsis and leads to M. persicae resistance, does not elicit the involvement of JA in aphid resistance. Stimulation of plants by harpin separates the roles of ET and JA in aphid defense. In harpin treated plants, ET no longer synergizes JA, as it does in plants under attack by aphids.

Similarly, JA, SA, ET, ABA, and GA have been demonstrated to induce the accumulation of $\mathrm{ROS} / \mathrm{H}_{2} \mathrm{O}_{2}$ in plant responses to aphid feeding (Smith and Boyko 2007), but the molecular mechanism underlying these interactions is not clear. Reactive oxygen species are elicitors of defense signaling pathways and are known to be involved in the elicitation of plant responses to aphid attack. As reported by Kuśnierczyk et al. (2008), little is known about the timedependent aspects of induced changes. Results have pointed to the involvement of ROS and calcium in early signaling, and SA and JA in the regulation of defense responses. Similarly, it has been suggested that activation of NADPH oxidase by wounding results in ROS bursting, including hydrogen peroxide. Hydrogen peroxide accumulation induces the subsequent biosynthesis of JA, 
leading to the expression of defense genes against insect feeding (Orozco-Cardenas et al. 2001; Turner et al. 2002). Signal transduction pathways can, however, be specific for the plant species and the tissue within a plant (Dicke and Van Poecke 2002).

\section{Conclusions and future directions}

Based on numerous presented reports concerning plantaphid interactions, the recognition of aphid feeding probes by plant receptors, and the ensuing plant defense responses are followed by the transmission of defense response signal cascades that involve various signaling molecules. Plant signaling pathways driven by jasmonic acid, salicylic acid, ethylene, abscisic acid, gibberellic acid, reactive oxygen species (ROS), and nitric oxide induce changes in the expression of defense genes, which lead to metabolic changes enhancing plant defenses in response to attack by aphids. Furthermore, the activation of transcription factors often enables a cross-talk between antagonistic and synergistic relationships between the pathways, and defines gene expression profiles of induced resistance. Additionally, it has been demonstrated that activation of signaling pathways is integrated and temporally controlled. Interactions between plants and insects are extremely complex. More studies are required to elucidate a detailed mechanism for the induction of plant defense responses to phloem-feeding insects such as aphids. More efforts to interpret the complex interactions among molecular regulators will pave the way to understanding the control mechanisms of defense events in plants.

A better understanding of the molecular mechanisms involved in the activation of plant signaling pathways, perception of signaling molecules, cross-talk relationships of these molecules in the plant defense signaling network and the main regulatory points such as transcription factors will supply new information for contemporary plant biology and may provide valuable data useful in the future generation of specific genetic modifications. Signaling events which mediate these different responses are of interest to plant scientists, not only because they are intrinsically biologically interesting, but because they are important from an agricultural perspective. An understanding of the interplay between the different defense pathways targeted towards different aphids is essential for the development of optimized crop protection strategies.

Open Access This article is distributed under the terms of the Creative Commons Attribution Noncommercial License which permits any noncommercial use, distribution, and reproduction in any medium, provided the original author(s) and source are credited.

\section{References}

Anderson JA, Peters DC (1994) Ethylene production from wheat seedlings infested with biotypes of Schizaphis graminum (Homoptera: Aphididae). Physiol Chem Ecol 23:992-998

Anstead J, Samuel P, Song N, Wu C, Thompson GA, Goggin F (2010) Activation of ethylene-related genes in response to aphid feeding on resistant and susceptible melon and tomato plants. Entomol Exp Appl 134:170-181

Argandona VH, Chaman M, Cardemil L, Munoz O, Zuniga GE, Corcuera LJ (2001) Ethylene production and peroxidase activity in aphid-infested barley. J Chem Ecol 27:53-68

Balbi V, Devoto A (2008) Jasmonate signalling network in Arabidopsis thaliana: crucial regulatory nodes and new physiological scenarios. New Phytol 177:301-318

Baumann L, Baumann P (1995) Soluble salivary proteins secreted by Schizaphis graminum. Entomol Exp Appl 77:57-60

Bernasconi ML, Turlings TCJ, Ambrosettli L, Bassetti P, Dorn S (1998) Herbivore-induced emissions of maize volatiles repel the corn leaf aphid, Rhopalosiphum maidis. Entomol Exp Appl 87:133-142

Bostock RM (1999) Signal conflicts and synergies in induced resistance to multiple attackers. Physiol Mol Plant Pathol 55:99-109

Boyko EV, Smith CM, Thara VK, Bruno JM, Deng Y, Sharon SR, Darsey KL (2006) Molecular basis of plant gene expression during aphid invasion: wheat Pto- and Pti-like sequences are involved in interactions between wheat and Russian wheat aphid (Homoptera: Aphididae). J Econ Entomol 99:1430-1445

Cao H, Bowling SA, Gordon AS, Dong X (1994) Characterization of an Arabidopsis mutant that is non-responsive to inducers of systemic acquired resistance. Plant Cell 6:1583-1592

Chaman ME, Copaja SV, Argandona VH (2003) Relationships between salicylic acid content, phenylalanine ammonia-lyase (PAL) activity, and resistance of barley to aphid infestation. J Agric Food Chem 51:2227-2231

Chang C, Stadler R (2001) Ethylene hormone receptor action in Arabidopsis. Bioessays 23:619-627

Chao Q, Rothenberg M, Solano R, Roman G, Terzaghi W, Ecker JR (1997) Activation of the ethylene gas response pathway in Arabidopsis by the nuclear protein ETHYLENE-INSENSITIVE3 and related proteins. Cell 89:1133-1144

Chen Z, Ricigliano JR, Klessig DF (1993) Purification and characterization of soluble salicylic acid binding protein from tobacco. Proc Natl Acad Sci USA 90:9533-9537

Chen YF, Randlett MD, Findell JL, Schaller GE (2002) Localization of the ethylene receptor ETR1 to the endoplasmic reticulum of Arabidopsis. J Biol Chem 277:19861-19866

Cherqui A, Tjallingii WF (2000) Salivary proteins of aphids; a pilot study on identification, separation and immunolocalization. J Insect Physiol 46:1177-1186

Conrath U, Chen Z, Ricigliano JR, Klessig DF (1995) Two inducers of plant defense response, 2, 6-dichloroisonicotinic acid and salicylic acid, inhibit catalase activities in tobacco. Proc Natl Acad Sci USA 92:7143-7147

Cooper WR, Goggin FL (2005) Effects of jasmonate-induced defenses in tomato on the potato aphid, Macrosiphum euphorbiae. Entomol Exp Appl 115:107-115

Creelman RA, Mulpuri R (2002) The oxylipin pathway in Arabidopsis. In: The Arabidopsis Book. American Society of Plant Biologists

de Bruxelles GL, Roberts MR (2001) Signals regulating multiple responses to wounding and herbivores. Crit Rev Plant Sci 20:487-521 
de Ilarduya MO, Xie QG, Kaloshian I (2003) Aphid-induced defense responses in $\mathrm{Mi}$-1-mediated compatible and incompatible tomato interactions. MPMI 16:699-708

De Vos M, Kim JH, Jander G (2007) Biochemistry and molecular biology of Arabidopsis-aphid interactions. BioEssays 29:871883

Dicke M, Van Poecke RMP (2002) Signalling in plant-insect interactions: signal transduction in direct and indirect plant defence. In: Plant Signal Transduction, Oxford University Press

Dillwith JW, Berberet RC, Bergman DK, Neese PA, Edwards RM, McNew (1991) Plant biochemistry and aphid populations: studies on the spotted alfalfa aphid, Therioaphis maculata. Arch Insect Biochem 17:235-251

Divol F, Vilaine F, Thibivilliers S, Amselem J, Palauqui JC, Kusiak C, Dinant S (2005) Systemic response to aphid infestation by Myzus persicae in the phloem of Apium graveolens. Plant Mol Biol 57:517-540

Doares SH, Narvaez-Vasquez J, Conconi A, Ryan CA (1995) Salicylic acid inhibits synthesis of proteinase-inhibitors in tomato leaves induced by systemin and jasmonic acid. Plant Physiol 108:1741-1746

Dong HP, Peng J, Bao Z, Meng X, Bonasera JM, Chen G, Beer SV, Dong H (2004) Downstream divergence of the ethylene signaling pathway for harpin-stimulated Arabidopsis growth and insect defense. Plant Physiol 136:3628-3638

Du H, Klessig DF (1997) Identification of a soluble, high-affinity salicylic acid-binding protein in tobacco. Plant Physiol 113: 1319-1327

Elliott DJ, Hodgson CJ (1996) The distribution of the vetch aphid on bean stems in relation to stylet length and phloem depth. Entomol Exp Appl 78:175-180

Ellis C, Karafyllidis I, Turner JG (2002) Constitutive activation of jasmonate signaling in an Arabidopsis mutant correlates with enhanced resistance to Erysiphae cichoracearum, Pseudomonas syringae, and Myzus persicae. MPMI 15:1025-1030

Fidantsef AL, Stout MJ, Thaler JS, Duffey SS, Bostock RM (1999) Signal interactions in pathogen and insect attack: expression of lipoxygenase, proteinase inhibitor II, and pathogenesis-related protein P4 in the tomato, Lycopersicon esculentum. Physiol Mol Plant Pathol 54:97-114

Flors V, Ton J, Mauch-Mani B (2009) Role of abscisic acid in disease resistance. In: Yoshioka K, Shinozaki K (Eds) Signal crosstalk in plant stress responses. Wiley-Blackwell, pp 1-22

Fujita Y, Fujita M, Yamaguchi-Shinozaki K, Shinozaki K (2009) Transcription factors involved in the crosstalk between abiotic and biotic stress-signaling networks. In: Yoshioka K, Shinozaki $\mathrm{K}$ (Eds) Signal crosstalk in plant stress responses. WileyBlackwell, pp 43-58

Gao LL, Anderson JP, Klingler JP, Nair RM, Edwards OR, Singh KB (2007) Involvement of the octadecanoid pathway in bluegreen aphid resistance in Medicago truncatula. MPMI 20:82-93

Giordanengo P, Brunissen L, Rusterucci C, Vincent C, van Bel A, Dinant S, Girousse C, Faucher M, Bonnemain JL (2010) Compatible plant-aphid interactions: how aphids manipulate plant responses? C R Biol 333:516-523

Girousse C, Moulia B, Silk W, Bonnemain JL (2005) Aphid infestation causes different changes in carbon and nitrogen allocation in alfalfa stems as well as different inhibitions of longitudinal and radial expansion. Plant Physiol 137:1474-1484

Godfrey LD, Holtzer TO (1991) Influence of temperature and humidity on European corn-borer (Lepidoptera, Pyralidae) egg hatchability. Environ Entomol 20:8-14

Goggin FL (2007) Plant-aphid interactions: molecular and ecological perspectives. Curr Opin Plant Biol 10:399-408

Guerreri E, Digilio MC (2008) Aphid-plant interaction: a review. J Plant Interact 3:223-232
Guo H, Ecker JR (2004) The ethylene signaling pathway: new insights. Curr Opin Plant Biol 7:40-49

Hardie JR, Issacs R, Pickett JA, Wadhams LJ, Woodcock CM (1994) Methyl salicylate and $(-)-(1 R, 5 S)$-myrtenal are plant-derived repellents from the black bean aphid, Aphis fabae Scop. (Homoptera: Aphididae). J Chem Ecol 20:2847-2855

Harmel N, Létocart E, Cherqui A, Giordanengo P, Mazzucchetlli G, Guillonneau F, De Pauw E, Haubruge E, Francis F (2008) Identification of pahid salivary proteins: a proteomic investigation of Myzus persicae. Insect Mol Biol 17:165-174

Hays DB, Porter DR, Webster JA, Carver BF (1999) Feeding behavior of biotypes $\mathrm{E}$ and $\mathrm{H}$ greenbug (Homoptera: Aphididae) on previously infested near-isolines of barely. J Eco Entomol 92:1223-1229

Heidel AJ, Baldwin IT (2004) Microarray analysis of salicylic acidand jasmonic acid signalling in responses of Nicotiana attenuata to attack by insects from multiple feeding guilds. Plant Cell Environ 27:1362-1373

Hori K (1976) Plant growth-regulating factor in the salivary gland of several heteropterous insects. Comp Biochem Phys 53B:435-438

Kawano T, Furuichi T, Muto S (2004) Controlled salicylic acid levels and corresponding signaling mechanisms in plants. Plant Biotechnol 21(5):319-335

Korth KL, Thompson GA (2006) Chemical signals in plants: Jasmonates and the role of insect-derived elicitors in responses to herbivores. In: Tuzun S, Bent E (eds) Multigenic and induced systemic resistance in plants. Springer, Inc., pp 259-278

Kuśnierczyk A, Winge P, Jørstad TM, Troczyńska J, Rossiter JT, Bones AM (2008) Towards global understanding of plant defence against aphids-timing and dynamics of early Arabidopsis defence responses to cabbage aphid (Brevicoryne brassicae) attack. Plant Cell Environt 31:1097-1115

Li J, Brader G, Palva ET (2004) The WRKY70 transcription factor: a node of convergence for jasmonate-mediated and salicylatemediated signals in plant defense. Plant Cell 16:319-331

Li Q, Xie QG, Smith-Becker J, Navarre DA, Kaloshian I (2006) Mi-1-mediated aphid resistance involves salicylic acid and mitogen-activated protein kinase signaling cascades. MPMI 19:655-664

Lorenzo O, Piqueras R, Sánchez-Serrano JJ, Solano R (2003) ETHYLENE RESPONSE FACTOR1 integrates signals from ethylene and jasmonate pathways in plant defense. Plant Cell $15: 165-178$

Mantelin S, Bhattarai KK, Kaloshian I (2009) Ethylene contributes to potato aphid susceptibility in a compatible tomato host. New Phytol 183:444-456

Matsuoka M (2003) Gibberellin signaling: how do plant cells respond to GA signals? J Plant Growth Regul 22:123-125

Mattson WJ, Scriber JM (1987) Nutritional ecology of insect folivores of woody plants: nitrogen, water, fiber, and mineral consideration. In: Slansky F, Rodriquez JG (eds) Nutritional ecology of insects, mites, spiders and related invertebrates. Wiley, New York, pp 105-146

McConn M, Creelman RA, Bell E, Mullet JE, Browse J (1997) Jasmonate is essential for insect defense in Arabidopsis. Proc Natl Acad Sci USA 94:5473-5477

Mello MO, Silva-Filho MC (2002) Plant-insect interactions: an evolutionary arms race between two distinct defense mechanisms. Braz J Plant Physiol 14:71-81

Mewis I, Appel HM, Hom A, Raina R, Schultz JC (2005) Major signaling pathways modulate Arabidopsis glucosinolate accumulation and response to both phloem-feeding and chewing insects. Plant Physiol 138:1149-1162

Meyer A, Miersch O, Büttner C, Dathe W, Sembdner G (1984) Occurrence of the plant growth regulator jasmonic acid in plants. J Plant Growth Regul 3:1-8 
Miles PW (1989) Specific responses and damage caused by Aphidoidea: principles. In: Minks AK, Harrewijn P (eds) Aphids: their biology, natural enemies and control. Elsevier, New York, pp 23-47

Miles PW (1999) Aphid saliva. Biol Rev 74:41-85

Miles PW, Oertli JJ (1993) The significance of antioxidants in the aphid-plant interaction: the redox hypothesis. Entomol Exp Appl 67:275-283

Miller HL, Neese PA, Ketring DL, Dillwith JW (1994) Involvement of ethylene in aphid infestation of barley. J Plant Growth Regul 13:167-171

Mohase L, van der Westhuizen AJ (2002) Salicylic acid is involved in resistance responses in the Russian wheat aphid-wheat interaction. J. Plant Physiol 159:585-590

Moloi MJ, van der Westhuizen AJ (2006) The reactive oxygen species are involved in resistance responses of wheat to the Russian wheat aphid. J Plant Physiol 163:1118-1125

Moloi MJ, van der Westhuizen AJ (2009) Involvement of nitric oxide during the Russian wheat aphid resistance. S Afr J Bot 75:412

Monaghan J, Weihmann, Li X (2009) Plant innate immunity. In: Baluska F, Vivanco (eds) Signaling and communication in plants. Springer, Berlin, pp 119-136

Moran PJ, Thompson GA (2001) Molecular responses to aphid feeding in Arabidopsis in relation to plant defense pathways. Plant Physiol 125:1074-1085

Moran PJ, Cheng Y, Cassell JL, Thompson GA (2002) Gene expression profiling of Arabidopsis thaliana in compatible plant-aphid interactions. Arch Insect Biochem Physiol 51:182-203

Morkunas I, Bednarski W (2008) Fusarium oxysporum induced oxidative stress and antioxidative defenses of yellow lupine embryo axes with different level of sugars. J Plant Physiol 165(3):262-277

Morkunas I, Marczak Ł, Stachowiak J, Stobiecki M (2005) Sucrosestimulated accumulation of isoflavonoids as a defense response of lupine to Fusarium oxysporum. Plant Physiol Biochem 43:363-373

Morkunas I, Narożna D, Nowak W, Samardakiewicz S, RemleinStarosta D (2011) Cross-talk interactions of sucrose and Fusarium oxysporum on the phenylpropanoid pathway and the accumulation and localization of flavonoids in embryo axes of yellow lupine. J Plant Physiol 168:424-433

Mutti NS (2006) Molecular studies of the salivary glands of the pea aphid, Acyrthosiphon pisum (Harris). PhD dissertation, Kansas State University

Nishimura N, Hitomi K, Arvai AS, Rambo RP, Hitomi C, Cutler SR, Schroeder JI, Getzoff ED (2009) Structural mechanism of abscisic acid binding and signaling by dimeric PYR1. Science 326:1373-1379

Orozco-Cardenas ML, Narvaez-Vasquez J, Ryan CA (2001) Hydrogen peroxide acts as a second messenger for the induction of defense genes in tomato plants in response to wounding, systemin, and methyl jasmonate. Plant Cell 13:179-191

Ozawa R, Arimura G, Takabayashi J, Shimoda T, Nishioka T (2000) Involvement of jasmonate- and salicylate-related signalling pathway for the production of specific herbivore-induced volatiles in plants. Plant Cell Physiol 41:391-398

Park SJ, Huang Y, Ayoubi P (2006) Identification of expression profiles of sorghum genes in response to greenbug phloemfeeding using cDNA subtraction and microarray analysis. Planta 223:932-947

Pena-Cortes H, Albrecht T, Prat S, Weiler EW, Willmitzer L (1993) Aspirin prevents wound-induced gene expression in tomato leaves by blocking jasmonic acid biosynthesis. Planta 191:123128

Penninckx IAMA, Thomma BPHJ, Buchala A, Metraux JP, Broekaert WF (1998) Concomitant activation of jasmonate and ethylene response pathways is required for induction of a plant defensin gene in Arabidopsis. Plant Cell 10:2103-2113

Perring TM, Holtzer TO, Toole JL, Norman JM, Myers GL (1984) Influences of temperature and humidity on pre-adult development of the banks grass mite (Acari Tetranychidae). Environ Entomol 13:338-343

Pettersson J, Pickett JA, Pye BJ, Quiroz A, Smart LE, Wadhams LJ, Woodcock CM (1994) Winter host component reduces colonization by bird-cherry-oat aphid, Rhopalosiphum padi (L.) (Homoptera, Aphididae), and other aphids in cereal fields. J Chem Eco 20:2565-2574

Pettersson J, Tjallingii WF, Hardie J (2007) Host-plant selection and feeding. In: van Emden HF, Harrington R (Eds) Aphid as crop pests. CAB International, pp 87-113

Ponder KL, Pritchard J, Harrington R, Bale JS (2001) Feeding behavior of the aphid Rhopalosiphum padi (Hemiptera, Aphididae) on nitrogen and water-stressed barley (Hordeum vulgare) seedlings. Bull Entomol Res 91:125-130

Prado E, Tjallingii WF (1997) Effects of previous infestation on sieve element acceptance by two aphids. Entomol Exp Appl 82:189200

Preston CA, Lewandowski C, Enyedi AJ, Baldwin IT (1999) Tobacco mosaic virus inoculation inhibits responses within but not between plants. Planta 209:87-95

Razem FA, El-Kereamy A, Abrams SR, Hill RD (2006) The RNAbinding protein FCA is an abscisic acid receptor. Nature 439:290-295

Riccardi F, Gazeau P, De Vienne D, Zivy M (1998) Protein changes in response to progressive water-deficit in maize. Quantitative variation and polypeptide identification. Plant Physiol 117:12531263

Robert-Seilaniantz A, Navarro L, Bari RJ, Jones JDG (2007) Pathological hormone imbalance. Curr Opin Plant Biol 10:372-379

Rossi M, Goggin FL, Milligan SB, Kaloshian I, Ullmanet al DE (1998) The nematode resistance gene $\mathrm{Mi}$ of tomato confers resistance against the potato aphid. Proc Natl Acad Sci USA 95:9750-9754

Sandström J, Telang A, Moran NA (2000) Nutritional enhancement of host plants by aphids-a comparison of three aphid species on grasses. J Insect Physiol 46:33-40

Schmelz EA, Engelberth J, Alborn HT, O'Donnell P, Sammons M, Toshima H, Tumlinson JH III (2003) Simultaneous analysis of phytohormones, phytotoxins, and volatile organic compounds in plants. Proc Natl Acad Sci USA 100:1809-1819

Shulaev V, Silverman P, Raskin I (1997) Airborne signalling by methyl salicylate in plant pathogen resistance. Nature 385:718721

Slaymaker DH, Navarre DA, Clark D, Del Pozo O, Martin GB, Klessig DF (2002) The tobacco salicylic acid-binding protein 3 (SABP3) is the chloroplast carbonic anhydrase, which exhibits antioxidant activity and plays a role in the hypersensitive defense response. Proc Natl Acad Sci USA 99:11640-11645

Slesak E, Slesak M, Gabrys B (2001) Effect of methyl jasmonate on hydroxamic acid content, protease activity, and bird cherry-oat aphid Rhopalosiphum padi (L.) probing behavior. J Chem Ecol 27:2529-2543

Smith CM, Boyko EV (2007) The molecular bases of plant resistance and defense responses to aphid feeding: current status. Entomol Exp Appl 122:1-16

Stotz HU, Koch T, Biedermann A, Weniger K, Boland W, MitchellOlds T (2002) Evidence for regulation of resistance in Arabidopsis to Egyptian cotton worm by salicylic and jasmonic acid signaling pathways. Planta 214:648-652

Telang A, Sandström J, Dyreson E, Moran NA (1999) Feeding damage by Diuraphis noxia results in a nutritionally enhanced phloem diet. Entomol Exp Appl 91:403-412 
Thaler J, Bostock R (2004) Interactions between abscisic acidmediated responses and plant resistance to pathogens and insects. Ecology 85:48-58

Thaler JS, Fidantsef AL, Duffey SS, Bostock RM (1999) Tradeoffs in plant defense against pathogens and herbivores: a field demonstration of chemical elicitors of induced resistance. J Chem Ecol 25:1597-1609

Tjallingii WF (2006) Salivary secretions by aphids interacting with proteins of phloem wound responses. J Exp Bot 57:739-745

Tjallingii WF, Hogen Esch TH (1993) Fine-structure of aphid stylet routes in plant-tissues in correlation with EPG signals. Physiol Entomol 18:317-328

Turner JG, Ellis C, Devoto A (2002) The jasmonate signal pathway. Plant Cell 14:153-164

Ueguchi-Tanaka M, Nakajima M, Katoh E, Ohmiya H, Asano K, Saji S, Hongyu X, Ashikari M, Kinato H, Yamaguchi I, Matsuoka M (2007) Molecular interactions of a soluble gibberellin receptor, GID1, with a rice DELLA protein, SLR1, and gibberellin. Plant Cell 19:2140-2155

Urbanska A, Tjallingii WF, Dixon AFG, Leszczyński (1998) Phenol oxidising enzymes in the grain aphid's saliva. Entomol Exp Appl 86:197-203

van de Ven WTG, LeVesque CS, Perring TM, Walling LL (2000) Local and systemic changes in squash gene expression in response to silverleaf whitefly feeding. Plant Cell 12:1409-1424

Van der Biezen EA, Jones JDG (1998) Plant disease-resistance proteins and the gene-for-gene concept. Trends Biochem Sci 23(12):454-456

van der Westhuizen AJ, Qian XM, Botha AM (1998) $\beta$-1,3-Glucanase in wheat and resistance to the Russian wheat aphid. Plant Physiol 103:125-131
Vasyukova NI, Ozeretskovskaya OL (2007) Induced plant resistance and salicylic acid: a review. Appl Biochem Microbiol 43:367373

Voelckel C, Weisser WW, Baldwin IT (2004) An analysis of plantaphid interactions by different microarray hybridization strategies. Mol Ecol 13:3187-3195

Walling LL (2000) The myriad plant responses to herbivores. J Plant Growth Regul 19:195-216

White TCR (1974) A hypothesis to explain outbreaks of looper caterpillars with special reference to populations of Slidosema suavis in a plantation of Pinus radiate in New Zealand. Oecologia 16:279-301

Will T, van Bel AJE (2006) Physical and chemical interactions between aphids and plants. J Exp Bot 57:729-737

Will T, Tjallingii WF, Thonnessen A, van Bel AJE (2007) Molecular sabotage of plant defense by aphid saliva. Proc Natl Acad Sci USA 104:10536-10541

Will T, Kornemann SR, Furch ACU, Tjallingii WF, van Bel AJE (2009) Aphid watery saliva counteracts sieve-tube occlusion: a universal phenomenon? J Exp Biol 212:3305-3312

Wojtaszek P (1997) Mechanisms for the generation of reactive oxygen species in plant defence response. Acta Physiol Plant 19:581-589

Yoshioka K, Shinozaki K (2009) Signal crosstalk in plant stress responses. Wiley-Blackwell, Ames

Zhu-Salzman K, Salzman RA, Ahn JE, Koiwa H (2004) Transcriptional regulation of sorghum defense determinants against a phloem-feeding aphid. Plant Physiol 134:420-431

Zhu-Salzman K, Bi JL, Liu TX (2005) Molecular strategies of plant defense and insect counter-defense. Insect Sci 12:3-15 